\title{
A case study of communication technology within the elementary school
}

Seryn Wyld

Ord Minnett Group Ltd

John Eklund

The University of Technology, Sydney

\section{Introduction}

Communication technologies, specifically the Internet and the World Wide Web (WWW), are rapidly expanding into both the educational and noneducational sectors. This advancement is providing new ways for people to communicate on a global scale and access vast amounts of information, in the case of the WWW, in a visually appealing and interactive manner.

The Internet is providing educators with the opportunity to implement a range of new teaching and learning practices. Opportunities for global communication and access to information are redefining classroom learning experiences, as this technology is providing students and teachers a medium through which the development of information handling skills and the use of student-centred learning may be utilised.

The use of the Internet and the WWW in the classroom is not only changing the design of the learning experiences, it is also redefining the emphasis on more traditional content-based curricula. Although this is essentially new to the majority of schools, a number of pioneering schools have proceeded to incorporate the Internet and the WWW into their existing teaching and learning practices.

It is the investigation of these exemplar schools that forms the focus of this article. We explore the application of the Internet and the WWW in the Australian elementary classroom. Through the review of current academic writing and the investigation into the efforts of a number of individual schools, the research identifies how many schools are presently utilising 
this technology, and reports on a range of consequences that are affiliated with the integration of information technology into education.

\section{Current uses of the Internet/WWW in education}

The bulk of information that exists on how schools are using the Internet and the WWW consists of individual success stories from a number of pioneering teachers. These case studies are presented in conference proceedings, journal articles and by educational organisations on the Internet. The nature of these reports relate a number of teacher and student experiences, highlight the advantages of using the Internet/WWW in education, and discuss a number of related issues and limiting factors.

There also exist a number of documents that report on pilot projects that have integrated the Internet and the WWW into a range of schools, such as the ACTEIN Project in Canberra (HRef 1), the Classrooms of the Future Project in Victoria (HRef 2), and the Apple Classrooms of Tomorrow Project (HRef 3 ) in the USA. These projects provide beneficial information on the use of information technology in the classroom, but from a context that is not representative of the 'everyday' classroom that does not have access to an advanced range of technology provided by these pilot projects. As a result, it is the purpose of this project to investigate the utilisation of Internet technology into the common 'everyday' classroom situation.

The majority of schools investigated have been using the Internet now for only a matter of months rather than years (NBEET 1996). A survey conducted by The Curriculum Corporation (Independent Education 1995) on the use of computing and communications equipment in 2,000 schools across Australia, has found that less than half of the primary schools surveyed had access to a modem and less than half of these schools did not have plans to use computer-mediated communication in the future. A similar survey in the United States (Heaviside et al 1995), has found that approximately $30 \%$ of US elementary schools have access to the Internet.

Despite the small amount of experience that schools have had with the Internet, there is almost universal enthusiasm about the potential of the Internet in education (NBEET 1996, p.vii). Teachers who are integrating the Internet and the WWW into their classroom are enthusiasts who have a desire to see this technology implemented into their classroom (Wyld 1996). It is these teachers who have persevered through many selfdedicated hours, to gain an understanding of this technology and learn how 
to integrate it into the classroom. It is also these teachers who have had a desire to share their experiences and their learning curves.

It has been found that the Internet and the WWW is being used in education in four main ways. These include (Wyld 1996):

- To communicate globally via email;

- To locate information on the WWW;

- To interact in global projects; and

- To publish material on the WWW.

\section{Email communication}

Email communication is one of the major uses of the Internet in primary education as it provides a fast, simple and achievable way for students and teachers to communicate with other people and schools in Australia and around the world. (Cooke 1996; Golden et al 1995; Hoggett 1996; JunionMetz 1995; NSW Department of School Education 1995; Peha 1995; Wyld 1996).

Email provides schools with a more affordable alternative to using the Internet, as it does not accrue connection or online costs that are associated with using the WWW. (Hoggett 1996; Golden et al 1995; Rayner 1996). Students and teachers use email to communicate with people both individually and as a group. (NSW Department of School Education 1995). Email is also used to communicate with field experts (Walters 1996a) and to aid professional development for teachers (Frazier \& Frazier 1994; Golden et al 1995).

\section{Searching for information on the WWW}

Teachers and students are using the WWW to access vast amounts of current information and resources from around the world that have previously not been available to schools in such quantities and with such ease (Brack 1996; Frazier \& Frazier 1994; Golden et al 1995; Junion-Metz 1996; NSW Department of Education 1995; Webb 1996; ACTEIN 1995). The most appealing aspect of accessing information through the WWW is that it is presented in a range of multimedia styles, such as text, graphics, sound and video, making the WWW very popular with students of all ages (Junion-Metz 1996).

Browsing and selecting appropriate information on the WWW requires students to acquire a number of research skills (Junion-Metz 1996; Russell 1996). Students must learn how to conduct successful WWW searches and 
be able to identify quality material and discriminate between the vast amount of information that is available (Frazier \& Frazier 1994).

\section{Publishing WWW pages}

The WWW is becoming an increasingly popular publishing vehicle that allows people to present information that is interesting and relevant to them, and that can be continually updated (Mernit 1995). For students, publishing WWW pages "is a way for them to express their ideas and information in an electronic, not paper, age." (Beaumont 1996). It enables students to be information providers, as opposed to information receivers (Pirlo 1996; Ismail 1996).

Publishing to a worldwide audience is an extremely motivating force for students (Russell 1996). It provides an opportunity for students to present their work in a new and innovative way (Rieck 1996; Rayner 1996). Students are able to experience the collaborative nature of the Internet by sharing their work with a worldwide audience and contributing to a worldwide collection of useful information (Junion-Metz 1996; NSW Department of School Education 1995; Mernit 1995; Pirlo 1996).

\section{Global projects}

Global projects are collaborative projects where students and teachers from around the world work on joint activities and communicate through the Internet (Junion-Metz 1996; Pirlo 1996). This worldwide collaboration is extremely motivating for both students and teachers as it provides an appealing way for students to gain Internet skills whilst engaged in regular classroom activities (Junion-Metz 1996).

Through the integration of global projects, students are encouraged to develop a range of skills relating to reading, writing and researching as well as developing their abilities in selecting, presenting and communicating information (Pirlo 1996). Global projects also enable students to gain an understanding of different cultures around the world and to view themselves as global citizens (Wyld 1996).

\section{The Internet - educational implications}

The Internet and the WWW are beginning to have a significant impact on all levels of education. This impact has the capacity to change the nature of teaching and learning practices as it provides the classroom with a range of new learning opportunities and experiences (Golden et al 1995; Oliver et al 1996; Rayner 1996; Webb 1996). The new learning experiences promoted 
by the Internet are a result of increasing access to vast amounts of current information and a means to instant global communication (Armstrong 1995; Fishman \& Pea 1994; NSW Department of Education 1995; Wise 1996).

The educational implications of the Internet will be outlined in the remainder of this section. In short, these include the ability of this technology to:

- Foster a range of different learning styles;

- Support an active, student-centred learning environment;

- Promote global relationships and cultural understandings;

- Promote real life experiences in the classroom;

- Provide a publishing medium;

- Promote parental and community involvement;

- Impact on the range of skills required by both students and teachers.

Communication technologies are capable of supporting a wide range of learning styles as information is presented in a range of ways that is flexible to students' individual needs and abilities (Papert 1994; Betts 1994). Students' learning can be significantly enhanced if they are able to utilise a particular characteristic of their own learning style as they engage in learning tasks. The opportunities promoted through the Internet and the WWW add meaning to a range of classroom experiences, by enabling students to become actively involved in classroom tasks and engage in real life contexts and solve real life problems (Wise 1996).

The use of communication technologies in the classroom is providing students and teachers with a new means of global communication where they can collaborate with different people around the world to share information and to work together on global projects (Peha 1995; Wyld 1996). This world-wide nature of the Internet is promoting the development of collaborative global relationships and cultural understandings by reducing the existence of stereotypes and prejudices and the significance of location, gender, age and race (Caudell 1994).

Communicating directly with other people from different parts of the world is extremely exciting and motivating for both teachers and students (Hoggett 1996; Walters 1996b). Email communication enables students to enhance their communication abilities, especially written communication (Cooke 1996; Hoggett 1996; Junion-Metz 1996; Peha 1995), whilst providing an opportunity for students to develop a greater understanding of different cultures and of themselves (Hoggett 1996). 
Collaborative learning has been widely researched and is found to significantly enhance student achievement and develop positive attitudes towards learning (Campbell et al 1992). Fishman \& Pea (1994) support the notion of collaborative learning, stating that "true power comes from the synergy of many dispersed minds working together to solve problems and discuss issues...”.

As previously mentioned, the publishing medium of the Internet is becoming an increasingly popular means for students to publish classroom work. This provides students with the ability to publish to a world-wide audience which is extremely motivating and is inspiring students to produce higher quality work (Russell 1996). This new form of electronic writing requires students and teachers to develop their communication and presentation skills (Howes 1996), which in the future may become necessary rather than optional, given that WWW publishing is becoming increasingly used (Nethercott 1996).

The Internet is providing greater opportunities for parents and the wider community to be involved in school activities. The increasing number of homes connecting to the Internet will allow students and parents to have better access to school resources and communication with teachers in the future (Peha 1995).

The impact of the Internet and the WWW in education has, and will continue, to fundamentally alter the role of teachers and students (JunionMetz 1996; NBEET 1996; Peha 1995). No longer is the teacher required to be the sole provider of information and "the font of all wisdom" (Caudell 1994, p.1). More emphasis is now being placed on the teacher to provide students with the necessary skills to know how to access and process information. This involves teachers taking on the roles of 'facilitator' and 'guide' to assist students to work through their own paths of learning (Dwyer 1994). Teachers will increasingly become co-learners with students as they engage in a range of new activities in the classroom (Armstrong 1995).

\section{The research project}

To gain further insight into the use of the Internet/WWW in primary education, the writers undertook a research project consisting of a number of teacher interviews, a survey and a case study.

The objective of the research project was to explore the issues and consequences related to the integration of the Internet and the WWW into primary education. This investigation provides an overall picture of how 
the Internet/WWW is being used in a number of different schools, why teachers are integrating this technology into education, and what opportunities are being presented to teachers and students.

The main components of the research project focussed on:

- What is involved in setting up the Internet/WWW in a school?

- How is the Internet integrated into classroom learning experiences?

- What are the students' opinions/feelings about the Internet/WWW?

- What are the teachers' opinions/feelings about the Internet/WWW?

- Does the Internet/WWW facilitate learning and how might this be achieved?

- What problems/issues are associated with integrating this technology into the classroom?

The research project consists of three consecutive strategies including:

- Teacher interviews;

- A survey; and

- A case study.

These three components have been designed to provide on-going development of the research topic throughout the research project. The teacher interviews were conducted to generate a feel for the research topic and lead into the development of the survey to provide a wider range of findings on the use of the Internet and the WWW in education. A case study was then conducted to provide first-hand insight and experience into a true context of using the Internet and the WWW in education.

\section{Teacher interviews}

Interviews were conducted with five classroom teachers/computer coordinators from different schools in NSW and Victoria who had been using the Internet and the WWW in their school for over six months. The purpose of these interviews was to establish a general feeling for how the Internet and the WWW is being used in various schools.

Specifically, the interviews were designed to establish:

- How teachers are using the Internet/WWW in the classroom;

- How schools have organised their Internet setup; 
- What are the teachers' opinions and feelings about the Internet/WWW in education; and

- What are the prominent issues relating to the integration of the Internet/WWW in education.

The teacher interviews provided the researcher with insight and understanding into the situation concerning the use of the Internet and the WWW in the primary classroom. Primarily the interviews resulted in the findings that:

- Teachers are primarily using the Internet/WWW in the classroom to search for information, communicate via email, engage in global projects and design WWW pages;

- The majority of teachers have received no professional training;

- Schools have received none or relatively little funding;

- The Internet/WWW is providing an innovative tool in the classroom that is extremely motivating;

- Teachers are using the Internet to enhance their personal and professional development.

These findings also contributed to the next component of the research project by assisting in the construction of a survey to be distributed to a range of teachers and educators. The questions in the survey were designed on the basis of the findings from the interviews, which enabled the researchers to develop more specific questions relating to the use and the issues of the use of Internet/WWW in education.

\section{Internet survey}

At the completion of the teacher interviews, an Internet survey was conducted to establish how a wider range of teachers and schools are utilising the Internet and the WWW in education and to identify the related issues. The survey was sent via email to over 100 individually selected schools and a number of listserv discussion groups throughout Australia and overseas. The content of the survey questions were specifically related to the:

- Duration and process of the school's Internet connection;

- Presence of teacher development programs/source of skill development;

- Use of the Internet/WWW in the classroom;

- Process of student evaluation whilst using the Internet/WWW;

- Problems/issues related to use of the Internet/WWW in the school;

- Overall perception; 
- Advantages/disadvantages of using the Internet/WWW in education.

Twenty-nine responses were received from the Internet survey. The findings, similar to those from the teacher interviews, suggest that (Wyld 1996):

- The main use of the Internet/WWW in schools is to search for information, as well as being used for email communication, to participate in global projects, and to a lesser degree, design WWW pages;

- The majority of schools have been connected to the Internet/WWW for approximately 12 months;

- Teachers have received little or no training;

- Schools have received none or relatively little funding;

- Teachers have not considered evaluation strategies related to students' use of the Internet/WWW;

- The Internet/WWW is providing an innovative tool in the classroom that is extremely motivating;

- Teachers feel the use of the Internet/WWW in education is extremely beneficial, but also identified a number of issues hindering its development, including student access to inappropriate material, cost, time and professional training;

- Teachers are using the Internet to enhance their personal and professional development.

The findings from the survey provided the writers with a further understanding of the concepts and issues relating to the use of the Internet/WWW amongst a wider population of schools and teachers. These findings equipped the researchers with the required knowledge and awareness to design and conduct the case study component of the research project. The focus of the case study, to examine the implementation of an Internet project in a class situation, was designed taking into account what teachers and students are currently doing with the Internet/WWW in the classroom and the presence of a number of related issues.

\section{Internet case study}

An Internet case study was conducted at a Sydney primary school with ten Year 6 students who took part in a two week Internet project called Project Atmosphere Australia (PAA) (HRef 4). PAA is an Internet project on weather that links a number of Australian schools in order to share real weather data and develop students' knowledge and understanding of weather concepts. 
The aim of the case study was to investigate the implementation of an Internet project in a primary school context. This case study allowed more sensitive data to be gathered on the use of the Internet/WWW in education.

The implementation of an Internet project was chosen to form the basis of the case study component, as the use of global projects, as determined from the previous research components, is a major way that the Internet/WWW is currently being used in education. Through the study of the Internet project, a number of factors relating to the use of the Internet/WWW, that were also highlighted in the previous components, could be investigated in more detail.

Primarily, the case study component of the research project was designed to:

- Identify the role that an Internet project plays in students' learning experiences;

- Identify the students' perceptions and opinions about using the Internet/WWW in education;

- Identify the issues relating to the use of the Internet/WWW in education; and

- Form conclusions about the integration of an Internet project into the school environment.

The Internet project was conducted over eight days within a two week period. The project involved students working in pairs on specific activities and as a whole group when involved in group discussions. The main activities in which the students were involved included:

- Making weather instruments;

- Collecting daily weather data;

- Forecasting weather;

- Finding weather patterns;

- Sending email messages;

- Receiving email messages;

- Comparing weather patters in different areas; and

- Sending questions to meteorologists by email.

On the first day of the project, students were assigned one or two weather instruments to make in pairs and were responsible for taking daily weather readings from their instruments and recording the data. Each day, the weather data was sent via email to the main project list for all the other 
participating schools to view. As email was received from other schools, the students, in pairs, selected a school with whom they would collect weather data from in order to do forecasts and make weather comparisons. At the end of the first week the students forecasted weather patterns for the following weekend at the school they had chosen to study and emailed their forecasts to the project list.

During the second week the students continued to take daily weather readings and identify a number of weather patterns. This was achieved by analysing and comparing the students' data and the data collected via email from other schools. Once the students had identified a number of weather patterns for both schools, they sent an email message to the project list informing the participating schools of their findings.

During the project students also proposed relevant questions that were sent via email to the online meteorologists. The students were also able to read questions sent by students from other schools which then prompted their own further questions and understanding.

The Internet project was evaluated by assessing to what extent the students had increased their knowledge of weather concepts and to what extent the project had facilitated their learning. This was achieved by conducting a group evaluation session with the students where they discussed different weather elements that they had learned and suggested activities and learning experiences that had helped them to enhance their learning. Immediately after the discussion session, the students were required to individually fill in evaluation sheets. The evaluation sheets also asked the students to describe weather elements they had learned, the activities that had helped them to learn and to identify what aspect of the project they liked and didn't like, and if they preferred to work in the manner prescribed by the Internet project.

The results of the case study are outlined below and include a number of quotes from the students involved in the project. The main results include:

- The students were highly motivated throughout the project

Throughout the project the students maintained a high level of enthusiasm and motivation. To the students, the project was seen as something different from their regular classroom work and an opportunity to be more involved with using the Internet.

"I learnt lots, very fun, challenging, very different."

"I thought it was fun doing the readings." 
- The students gained knowledge on the weather concepts

During the project the students gained knowledge on different aspects of weather. This included knowledge on specific cloud types, their characteristics and further clarification on air pressure and how high and low pressure systems affect the weather. The students also gained an understanding on how to forecast the weather and what elements affect the weather, and to identify a range of weather patterns and relationships that were similar and different in varying places around Australia.

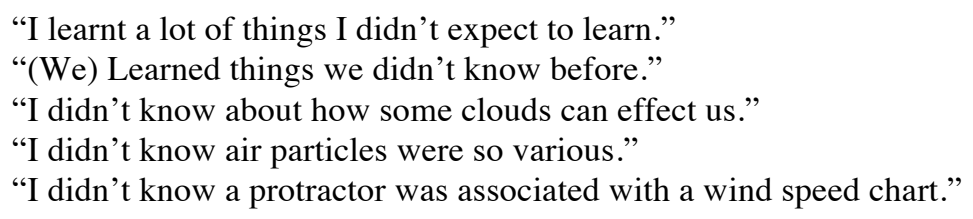

- The students gained knowledge relating to the Internet and the WWW

The project enabled all students to gain a better understanding of what the Internet and the WWW is and how it can be used. The students experienced the advantages of collaborating with different people from different places to share and obtain new information and ideas.

"Know how to send things (by email)."

"(Learnt) how to use the Internet"

"We learnt more about the web, email..."

- The range of project activities promoted student learning

A number of activities were identified that promoted the student's learning throughout the project. These activities include:

- discussions with project teacher and other students

- making weather instruments

- measuring weather elements

- using email to send and compare data

- forecasting from other school's data

- looking for weather patterns

- sending questions to experts and receiving answers

"Making the instruments, forecasting for other schools and using Internet (helped me learn)"

"Sending and receiving email, comparing data, forecasting, teacher." 
- Student participation and involvement encouraged learning

Having the students begin the project by making their own weather instruments was extremely motivating and gave the students a sense of ownership to the project. They were proud of their creations and were eager to find out if they would work and what readings they would obtain. This enabled the students to know exactly what measurements they were responsible for taking each day and to understand how these measurements were obtained.

"Building the instruments - helped us learn about weather."

"Making and using the instruments that we made."

- Working collaboratively assisted learning

Throughout the project the students worked very well together in both pairs and as a whole group. The students stated that they preferred to work with other students rather than on their own as this helped them to achieve the required tasks more quickly and easily and to experience more ideas and suggestions. Through discussions with their partner and the other students, they were able to receive a greater amount of reinforcement and understanding of their own ideas.

"Being in a group is better because you get more ideas from people and so we could do it better."

"I like working with other people because you get 2 points of view"

"(Like to work) with other people because if I don't know what to do I find out."

"(Like to work) with others, because you get more ideas, faster."

- Communication between students and schools provided a sense of reality to the project

As the students were working with their own data that they had collected and the data from other schools the project was made more realistic and personal. Knowing that their results were being sent to an audience encouraged their participation and involvement. Receiving feedback from the other schools and from the project coordinator provided an opportunity for the students to obtain real feedback on their findings, to see how they were progressing and to further clarify their understandings. The students found that being able to communicate by email with meteorologist experts provided a fast and efficient way to seek answers, clarify their learning and prompt further questioning. 
"... it is useful to find other opinions other than people you know."

"It is useful to work with other schools"

"... you can compare data."

"Sending questions to scientists (assisted learning)."

- Global communication with real people increased cultural understandings

The project provided an opportunity for the students to communicate with different people and to learn more about people and places around Australia. Through this collaboration the project developed a greater sense of purpose as the students were dealing with real data and a real audience.

“... we got to learn about other schools' weather."

"(Is useful to work with other schools) to compare your work and learn more about their climate and weather."

"It was a good way to get to know people."

"It gives others a chance to see what you have done."

"We try harder to impress them (audience)."

- Global communication provides more ideas and information

By communicating with different groups of people, the students were able to draw on a range of experiences and ideas from other schools and students and to see how differently the schools were involved in the project.

"(Without the Internet) we wouldn't have found out as much."

"You can communicate with people around the world."

"You could share your knowledge."

- Email provides a fast and efficient way to communicate

By using email the students were able to quickly and efficiently send messages to other schools and receive responses. A number of questions were sent to online meteorologists who replied to the students' queries within 24 hours. These responses often initiated further questioning.

"It's (email) quick."

"It (Internet) gave me more ideas, has lots of information, email is quicker than post."

"(Internet) helped us by the questions we asked in email and quick with sending." 
- Students need skills and guidance when using the Internet/WWW

At the beginning of the project the students had to be taught how to use the modem and how to compose an email message. Often the students would forget to dial into the modem before accessing the email program. The students did not have fast typing skills and thus the process of sending email was very slow.

"(Learnt) that you can't get on to email without an address."

- One Internet connection in the school does not provide enough access to students and teachers

As the school has only one Internet connection, not enough time was able to be provided to the students to use the Internet and to access information on the WWW during the project. Also contributing to this factor was that the project teacher was not the regular classroom teacher and could not assign other times during the day for the students to use the Internet or to do specific activities. Primarily, when the Internet/WWW was used during the project, the students had to use it in conjunction with another class in the computer room. If each classroom had their own Internet connection the project would be able to be better integrated into the classroom work and not take up as much time as students could access their email and the WWW during different times of the day. Students would also have better access to the WWW to locate current satellite images and weather forecasts and to view selected WWW pages to gain further understanding of different weather elements.

"We didn't use it (Internet) much."

"More Internet connections (would make the project better)."

"(Need) more computers with modems. There's only one computer that has a modem."

"It's expensive - that's what stops our school not having more."

"(Project was) a bit hard (and there was) not enough time."

"We had no time to use the Web."

"Didn't have enough time each day."

- Technology problems are common and must be catered for

Due to problems with the school's network, email messages were not able to be printed at the school to be passed on to particular students. As well, due to limited access, selected WWW sources were printed from the WWW by the project teacher and given to the students. 
- Due to project organisation, amount of classroom implementation and follow-up was less than desired

Although the duration of the project was for only two weeks, the students made a number of achievements and experienced a range of worthwhile activities. If the project was extended for a longer period of time, the students would have continued to gain more experiences and the project could have been extended into a range of other areas.

- The project received positive feedback and comments

The school's Computer Coordinator said that the project was extremely worthwhile and that the students benefited a great deal from being involved. The project was mentioned in the school's newsletter and the students created a PAA WWW page to be linked to their school's web page. The PAA Coordinator also commented that the students made significant achievements and provided excellent contributions to the project.

"I (PAA Coordinator) am somewhat stunned by the students at [school] and their intrepid forecasting! Very well done! They may just win the "Amateur Forecasters' award for this project."

\section{Conclusion}

The research project has identified that the learning opportunities presented by the Internet and the WWW can significantly enhance students' learning. These opportunities provide students with an interactive learning environment that supports a range of individual learning styles and promotes the development of a number of information processing skills. This technology is further allowing students to engage in collaborative learning and is promoting the inclusion of real life learning experiences in the classroom.

Although the implementation of the Internet and the WWW into education, in theory, seems straightforward and unquestionable, the findings from this research project suggest that, in reality, this is not the case. The research has identified a number of issues hindering the implementation of the Internet and the WWW into education. These issues include:

- Lack of teacher development programs;

- Lack of available funds and resources;

- Student access to inappropriate material on the Internet; 
- Lack of time dedicated to Internet usage;

- Lack of Internet access; and

- Developing awareness of associated ethical issues.

The majority of Government initiatives to integrate the Internet and the WWW into education are premature for most schools. These initiatives have been primarily concerned with establishing Internet connections within schools, before the provision of adequate training programs and the coordination of related policy documents. Thus without the presence of these two elements, the integration of this technology will not result in amore significant impact on students' learning.

Lack of professional development programs associated with the use of information technology contributes to the poor levels of teacher awareness and significantly impedes the development of technology into education (Cotter 1996; Independent Education 1995; Coppinger \& Hocking 1996). As well, the limited number of Internet connections in schools, which primarily consists of one connection, and the lack of appropriate funding and resources is also limiting the development of this technology into education.

Thus the provision of appropriate teacher development programs and sufficient access to the Internet have been identified as the means to achieving greater integration of the Internet and the WWW into education. The research has also identified a number of recommendations for schools and teachers to promote the success of the Internet in students' education. These recommendations include:

- Conduct professional development programs for teachers;

- Provide ongoing support and training for teachers;

- Integrate the Internet into classroom projects as another information tool;

- Allow students to work collaboratively and communicate with other Internet users;

- Establish more Internet connections that are located throughout the school;

- Involve the community in the promotion of the Internet and to raise funds;

- Utilise curriculum support documents and Internet educational sites.

In the future, greater impact of communication technologies in education will eventually alter the structure of current curricula to provide for the new opportunities presented by the use of this technology in education. 
Essentially, it is not technology alone that is influencing the nature of education, rather it is the way this technology can be used to redefine the learning experiences presented to students in the classroom (Means \& Olson 1994).Through these new opportunities, educators will be able to incorporate more meaningful learning experiences which are more reflective of students' everyday experiences in society and incorporate the use of society's tools (Davidson 1995; Duffy \& Jonassen 1992).

\section{References}

Australian Capital Territory Education Information Network (ACTEIN) (1995). http://freenet.actein.edu.au/

Armstrong, S. (1995). Telecommunications in the Classroom, (2nd edn.), Computer Learning Foundation and International Society for Technology in Education (ISTE), USA.

Beaumont, G. (1996). Why Have Your Students Create Web Pages? Tucker Box (Toss $U p$ ), Department of Education Queensland. http://www.uq.edu.au/!zzdpedwe/tucker/articles/

Betts, F. (1994). On the Birth of the Communication Age: A Conversation with David Thornburg. Educational Leadership, 51(7).

Brack, C. (1996). Linking the Data to Develop Knowledge: A Neglected Part of Developing WEB-based University Resources. Paper presented to AusWeb 96, Gold Coast, Queensland, 7-9 July 1996.

Campbell, L., Campbell, B. \& Dickinson, D. (1992). Teaching and Learning Through Multiple Intelligences. Hawker Brownlow Education, Australia.

Caudell, L. (1994). The Global Classroom. Northwest Regional Educational Laboratory, February 1994. ERIC ED 369385.

Cooke, M. (1996). Networking Across The Globe. In Gateways: Information Technology in the Learning Process. Commonwealth of Australia, ACT.

Coppinger, B. \& Hocking, A. (1996). Footprints. The Whalesong Foundation / I*EARN Australia. http://www.peg.apc.org/ iearn/gcp/gcresources.html

Cotter, L. (1996). Professional Development and the Networked School. Independent Education, 26(3).

Davidson, K. (1995). Education in the Internet - Linking Theory to Reality. http://www .oise.on.ca/ kdavidson/cons.html 
Duffy, T. M. \& Jonassen, D. (eds.) (1992). Constructivism and the Technology of Instruction. Lawrence Erlbaum Associates, Inc., USA.

Dwyer, D. (1994). Apple Classrooms of Tomorrow: What we've learned. Educational Leadership, 53(2).

Fishman, B. \& Pea, R. (1994). The Internetworked School: A Policy for the Future. http://www.gsn.org/web/issues/aup/Fishman.htm

Frazier, G. \& Frazier, D. (1994). Telecommunications and Education: Surfing and the Art of Change. National School Boards Association, VA, USA.

Golden, P. S., Vasaturo, R. \& Wallet, K. B. (1995). The Educator's Guide to the Internet, (2nd edn.). Virginia Space Grant Consortium, Hampton, VA, USA.

Heaviside, S. (1995). Advanced Telecommunications in US Public Schools. Weststat, Inc., Rockville, MD., ERIC ED 378959.

Hoggett, B. (1996). Towards - 2000. In Gateways: Information Technology in the Learning Process. Commonwealth of Australia, ACT.

Howes, D. (1996). The Significance of Difference: A Consideration of Hypertext and Other Technologies. http://www.srl.rmit.edu.au/vate/idiom/david.htm

Independent Education (1995). How Much Computer Equipment is Being Used in Australian Schools? Independent Education, 25(4).

Ismail, J. (1996). 100 Questions about Australia. In Gateways: Information Technology in the Learning Process. Commonwealth of Australia, ACT.

Junion-Metz, G. (ed.) (1996). K-12 Resources on the Internet Plus An Instructional Guide. Gail Junion-Metz, Berkeley, CA, USA.

Means, B. \& Olson, K. (1994). The Link Between Technology and Authentic Learning, Educational Leadership, 51(7).

Mernit, S. 1995) Publishing on the WWW: What's Happening Today and What May Happen in the Future. http://inet.edu.gov/ gsolomon/mernit.html

National Board of Employment, Education and Training (1996). Management of Student Access to Controversial Material on the Internet. Commissioned Report No.48. Australian Government Publishing Service, Canberra.

Nethercott, D. (1996). Expanding Your Horizons Without Blowing Your Mind. Paper presented to Australian Computers in Education Conference, Canberra, 9-12 April 1996.

NSW Department of School Education (DSE) (1995). Connect.edu, Internet in the Classroom (Draft). NSW Department of School Education, Sydney. 
Oliver, R., Herrington, J., \& Omari, A. (1996). Creating Effective Instructional Materials for the World Wide Web. Paper presented to AusWeb 96, Gold Coast, Queensland, 7-9 July 1996.

Papert, S. (1994). The Children's Machine: Rethinking School in the Age of the Computer. Harvester Wheatsheaf.

Peha, J. (1995). How K-12 Teachers Are Using Computer Networks. Educational Leadership, 53(2).

Pirlo, B. (1996). An Interesting Experience. Tucker Box (TossUp), Department of Education Queensland. http://www.uq.edu.au/!zzdpedwe/tucker/articles/

Rayner, R. (1996). Newbies Internet Experience. TuckerBox (Toss Up), Department of Education Queensland, http://www.uq.edu.au/!zzdpedwe/tucker/articles/

Rieck, B. (1996). Newbies Internet Experience. Tucker Box (TossUp), Department of Education Queensland. http://www.uq.edu.au/!zzdpedwe/tucker/articles/

Russell, J. (1996). Newbies Internet Experience. Tucker Box (Toss Up), Department of Education Queensland. http://www.uq.edu.au/!zzdpedwe/tucker/articles/

Walters, C. (1996a). Murder Under the Microscope. In Gateways: Information Technology in the Learning Process. Commonwealth of Australia, ACT.

Walters, C. (1996b). Expedition Icebound. In Gateways: Information Technology in the Learning Process. Commonwealth of Australia, ACT.

Webb, C. (1996). Hypertext and the Construction of Individual Narratives: Implications for Socially Constructed Curriculum in Primary Schools. Paper presented to AusWeb 96, Gold Coast, Queensland, 7-9 July 1996.

Wise, N. (1996). Using Technology to Integrate Learning into the Real World. Paper presented to Australian Computers in Education Conference, Canberra, 9-12 April 1996.

Wyld, S. (1996). Success Models for the Integration of the WWW in Primary Education. Paper presented to AusWeb 96, Gold Coast, Queensland, 7-9 July 1996. 


\title{
Hypertext references
}

HRef 1: The Australian Capital Territory Education Information Network (ACTEIN). http://freenet.actein.edu.au/

HRef 2: Classrooms of the Future Project. http://www.dse.vic.gov.au/cofinits.htm

HRef 3: ACOT (Apple Classrooms of Tomorrow) Project.

http://www.education.apple.com/

HRef 4: Project Atmosphere Australia (PAA).

http://owl.qut.edu.au/oz-teachernet/projects/ paa/paa.html

\author{
Seryn Wyld \\ Ord Minnett Group Ltd \\ Tel: +61 292203281 Fax: +61292201470 \\ email: swyld@ords.com.au \\ John Eklund \\ Faculty of Education, The University of Technology, Sydney \\ Tel: +61295145613 Fax: +61295145666 \\ email: j.eklund@UTS.edu.au
}

